\title{
BMJ Open Epidemiology of pertussis-related paediatric intensive care unit (ICU) admissions in Australia, 1997-2013: an observational study
}

\author{
Marlena C Kaczmarek, ${ }^{1,2}$ Robert S Ware, ${ }^{1,2}$ Julie A McEniery, ${ }^{3}$ \\ Mark G Coulthard, ${ }^{3,4}$ Stephen B Lambert ${ }^{1,5}$
}

To cite: Kaczmarek MC Ware RS, McEniery JA, et al. Epidemiology of pertussisrelated paediatric intensive care unit (ICU) admissions in Australia, 1997-2013: an observational study. BMJ Open 2016;6:e010386. doi:10.1136/bmjopen-2015010386

- Prepublication history for this paper is available online. To view these files please visit the journal online (http://dx.doi.org/10.1136/ bmjopen-2015-010386).

Received 27 October 2015 Revised 19 February 2016 Accepted 3 March 2016

CrossMark

For numbered affiliations see end of article.

Correspondence to Marlena C Kaczmarek; m.kaczmarek@uq.edu.au

\section{ABSTRACT}

Objective: To review the epidemiology of pertussisrelated intensive care unit (ICU) admissions across Australia, over a 17 -year period.

Design: Retrospective descriptive study.

Setting: Australian ICUs contributing data to the Australian and New Zealand Paediatric Intensive Care (ANZPIC) Registry. The number of contributing ICUs increased over the study period, from 8 specialist paediatric ICUs in 1997 to 8 specialist paediatric and 13 general ICUs in 2013.

Participants: All paediatric ( $<16$ years) ICU admissions, coded as pertussis-related, between 1 January 1997 and 31 December 2013.

Results: A total of 373 pertussis-coded ICU admissions were identified in the ANZPIC Registry over the study period. Of these cases, $52.8 \%$ occurred during the 4 years of the recent Australian epidemic (2009-2012). ICU admissions were most likely to occur in infants aged younger than 6 weeks $(41.8 \%$, $\mathrm{n}=156)$ and aged 6 weeks to 4 months $(42.9 \%$, $n=160$ ). The median length of stay for pertussisrelated ICU admissions was 3.6 days, with $77.5 \%$ of cases staying in ICU for $<7$ days. Approximately half of all admissions $(54.8 \%)$ required some form of respiratory support, with $32.7 \%$ requiring invasive respiratory support. Over the study period, 23 deaths were recorded $(6.2 \%$ of pertussis-related ICU admissions), of which $20(87.0 \%)$ were infants $<4$ months old.

Conclusions: Pertussis-related ICU admissions occur primarily in infants too young to be fully protected from active immunisation. More needs to be done to protect these high-risk infants, such as maternal immunisation.

\section{INTRODUCTION}

Pertussis, or whooping cough, is a highly infectious bacterial respiratory infection caused by the gram-negative bacterium, Bordetella pertussis. It continues to be responsible for a high burden of disease across all

\section{Strengths and limitations of this study}

- We describe the epidemiology of Australian pertussis-related paediatric intensive care unit (ICU) admissions over a 17-year period. To date, research on severe pertussis infections in Australia has often been limited to a single state and specific epidemic period.

- We used data collated in the Australian and New Zealand Paediatric Intensive Care (ANZPIC) Registry, which collects detailed paediatric intensive care patient episode information from contributing specialist paediatric ICUs (PICUs) as well as general ICUs (which admit mainly adult and some paediatric patients) across Australia and New Zealand.

- Any admissions to ICUs not contributing in the ANZPIC Registry would have been missed in our analysis, however, the number of missing cases is expected to be low as all eight large specialist PICUs (which account for the vast majority of Australian PICU admissions) have participated in the ANZPIC Registry since 1997.

- Our study used data from an existing database, and did not include a medical chart review or diagnostic testing results. It was therefore entirely reliant on the accuracy of existing coding.

age groups in Australia and overseas, despite long-term vaccination programmes. ${ }^{1}$

Infants aged $<6$ months, and unvaccinated individuals, have the highest risk of severe infection, and commonly require hospitalisation. $^{2}$ As such, a primary goal of pertussis immunisation has been to minimise severe illness and deaths, particularly in infants. ${ }^{3}$ Despite concerted efforts, severe cases (requiring hospitalisation and/or ICU admission) and deaths continue to occur. ${ }^{4-6}$

Pertussis vaccination was included on the first Australian National Immunisation Schedule in 1975 , however, pertussis vaccine 
has been used in Australia since 1942 in state-based programmes. ${ }^{7}$ Vaccine formulations and scheduled doses have changed over time. ${ }^{7}$ Currently, pertussis-containing vaccine doses are administered as a primary series at 6 weeks, 4 months and 6 months, followed by booster doses at 4 and 15 years. ${ }^{3}$ In March 2015, reintroduction of the 18-month booster was recommended, with implementation of this dose starting in October 2015. In addition, to active immunisation, both cocoon and maternal vaccination have been nationally recommended to further reduce spread to young infants, with variable timing of introduction in different states. ${ }^{7}$ Cocoon vaccination requires immunisation of the close/regular contacts of a newborn infant to reduce the risk of exposure, while maternal vaccination (during the third trimester of pregnancy) allows transfer of antibodies to the fetus, and provides protection from the time of birth. ${ }^{3}$

Research on severe pertussis infections-requiring hospitalisation or ICU admission, and/or causing death -in Australia has been limited, often restricted to a single state and specific epidemic period. ${ }^{4-6}{ }^{8-11}$ As such, there is little information available in the published literature about the epidemiology of severe pertussis infections at a national level over a time period that includes both epidemic and interepidemic periods, making historical and international comparisons difficult. The aim of this study was to describe Australian paediatric pertussis-related ICU admissions, using a large national data set, over a 17-year period that incorporated epidemic and interepidemic periods.

\section{METHODS}

We conducted a retrospective descriptive study using data collated in the Australian and New Zealand Paediatric Intensive Care (ANZPIC) Registry between 1997 and 2013. The ANZPIC Registry was established in 1997 and collects paediatric intensive care patient episode information from contributing specialist paediatric ICUs (PICUs) as well as general ICUs (which admit mainly adult and some paediatric patients) across Australia and New Zealand. ${ }^{12}$ In 1997, eight PICUs from five Australian states (New South Wales (NSW), Queensland (QLD), South Australia (SA), Victoria (VIC), Western Australia (WA) ) contributed data to the ANZPIC Registry. ${ }^{12}$ By 2013, one additional PICU (in Tasmania (TAS)) and 13 ICUs (representing all states/territories) were participating. The original eight PICUs, of which seven have contributed data continuously since commencement (eighth contributed in 1997-2008 only), accounted for an annual average of $93 \%$ of admissions recorded in the ANZPIC Registry between 1997 and 2013 (1997 value: $100 \%$, 2013 value: $84 \%$ ).

Participating ICUs collect data in real-time either on a Microsoft Access database (Microsoft Corp, Redmond, Washington, USA) supplied by the ANZPIC Registry, or onto their local clinical information system (amended to include required ANZPIC Registry variables). Data are submitted to the centrally administered ANZPIC Registry electronically every 6 months. ${ }^{12}$

A single record is created for each ICU admission and includes demographic data, physiological variables measured at the time of first face-to-face contact between the patient and ICU doctor, the ICU/hospital outcomes and length of stay, as well as the type and duration of respiratory support. ${ }^{12}$ Admissions are defined using ANZPIC Registry-specific diagnosis codes (standardised across all participating sites) ${ }^{13}$ and include 'principal diagnosis' (the diagnosis most directly responsible for the ICU admission), 'underlying diagnosis' (the principal underlying diagnosis contributing to the need for ICU admission), and up to seven 'associated diagnoses'. Associated diagnoses are conditions additional to the principal and underlying reasons that contributed to the ICU admission, and can include other syndromes, diseases, abnormalities or diagnoses identified on or during ICU admission. The treating clinician is responsible for selecting the appropriate diagnostic codes for each admission, and coding may be based on clinical symptoms, diagnostic test results, or a combination of both. Results of any diagnostic tests performed, including respiratory virus/bacteria detection, are not captured within the ANZPIC Registry. Immunisation history is also not collected.

For this study, we extracted ANZPIC Registry data for all Australian paediatric (aged 0 to $<16$ years) ICU admissions between 1 January 1997 and 31 December 2013 with diagnosis codes of ' 470 - pertussis syndrome' or '720-pertussis' occurring in any of the diagnosis fields. The deidentified line-listed data extract included patient demographic variables (age, sex, ethnicity, state), and hospital and ICU admission details including admission/discharge dates, diagnoses (principal, underlying and associated), discharge/outcome and respiratory support variables (type and duration of respiratory support). Respiratory support was defined as any intervention to support respiratory function and includes both non-invasive and invasive methods. Some patients may have required combinations of both invasive and non-invasive support during their ICU admission. Non-invasive respiratory support includes continuous positive airway pressure, biphasic positive airway pressure, negative pressure ventilation, and high-flow nasal cannula, while invasive respiratory support is mechanical ventilation delivered by endotracheal intubation or tracheostomy.

Data were aggregated during analysis, including grouping by 4-year periods (1 January 1997-31 December 2000; 1 January 2001-31 December 2004; 1 January 2005-31 December 2008; 1 January 2009-31 December 2012), except for 2013 (presented as single-year data: 1 January 2013-31 December 2013), and chronological age. Admissions were classified as having co-detection if they had any other respiratory infection diagnosis code in any diagnostic field (in addition to one of the two pertussis codes). Cases were categorised as being premature 
(gestational age) if the code ' 826 - Prematurity $(<37 / 40$ and $<12$ months of age)' was included in any diagnosis field. Comorbidity was defined by the inclusion of a diagnostic code (in any diagnosis field) for any congenital cardiovascular and/or respiratory abnormality, chronic lung disease, asthma or cystic fibrosis.

In Australia, pertussis is a nationally notifiable condition, and all cases that meet the case definition are required to be reported to the relevant State or Territory Health Department in accordance with public health legislation. ${ }^{14}$ We obtained national pertussis notification data between 1 January 1997 and 31 December 2013 for children aged < 16 years from the Australian Government Department of Health. Using mid-year Australian Bureau of Statistics population estimate data, ${ }^{15}$ we calculated the incidence of pertussis notifications (in children $<1$ year and children 1 to $<16$ years) per 100000 age-specific population, and compared this with the incidence of pertussis-related ICU admissions per 100000 age-specific population.

Stata V.12 (StataCorp, College Station, Texas, USA) was used for data analysis. Descriptive statistics were calculated, including means, medians and standard deviations (SDs). The association between patient characteristics and outcomes was investigated using a Student t-test (continuous variables) and risk ratios (categorical variables).

\section{RESULTS}

Between 1 January 1997 and 31 December 2013, there were 373 pertussis-related ICU admissions out of a total 113197 all-cause ICU admissions recorded in the ANZPIC Registry (table 1). Of pertussis-related ICU admissions, $83.9 \%(\mathrm{n}=313)$ were admitted to PICUs, and the remaining $16.1 \%(\mathrm{n}=60)$ were admitted to general ICUs, however $78.3 \% \quad(\mathrm{n}=47)$ of the general ICU admissions occurred in 2009-2012. There were 4 years where the annual case number was higher than 40 , all recorded between 2009 and 2012 (2009 $\mathrm{n}=46$; 2010 $\mathrm{n}=47 ; 2011 \mathrm{n}=59 ; 2012 \mathrm{n}=45$ ), compared with a range of 4-26 cases per year in other years (figure 1 ).

Overall, the majority of cases $(84.7 \%, \mathrm{n}=316)$ were infants aged <4months, of whom approximately half $(n=156)$ were aged $<6$ weeks. The median age at the time of admission was 48 days (range 0 days to 15.9 years). There were 28 cases $(7.5 \%)$ aged over 12 months, and the median age among these cases was 3.1 years (range $1.0-15.9$ years).

The incidence of ICU admissions and notifications in children $<1$ year and 1 to $<16$ years all followed a similar trend and all peaked in 2011 (figure 2). The incidence of ICU admissions in children 1 to $<16$ years remained low $(<0.2$ per 100000 population per year) over the study period. Notifications and ICU admissions in children aged $<1$ year were highly correlated (correlation coefficient $=0.96$ ).
The most common principal diagnoses coded for pertussis-related ICU admissions were 'pertussis syndrome' (41.3\%), 'apnoea' (12.6\%), 'pneumonia/pneumonitis' (10.7\%), 'bronchiolitis' $(9.1 \%)$ and 'respiratory failure' $(5.4 \%)$. The diagnosis codes used to identify pertussis-related admissions, 'pertussis syndrome' and 'pertussis', were both used in $28.7 \%(\mathrm{n}=107)$ of cases, and were used alone in 25.7\% $(\mathrm{n}=96)$ and $45.6 \%$ $(\mathrm{n}=170)$ of cases, respectively. Although the relative proportions fluctuated from year to year, there was no preferential trend over time for using either one or both codes, and they appeared to have been used interchangeably. Prematurity (defined as birth $<37$ weeks gestation) was coded in 45 cases $(12.1 \%)$, however, among cases aged $<1$ year, prematurity was not associated with significant differences in length of ICU stay $(p=0.74)$, duration of both any or invasive respiratory support ( $\mathrm{p}=0.92$ and 0.70 , respectively), or death $(\mathrm{p}=0.23)$. Comorbidities were coded in $6.7 \% \quad(n=25)$ of cases, of which congenital cardiovascular conditions were present in 12 cases, chronic lung disease in 6, and asthma in 5. Three cases coded as having comorbidities were also premature. No trend in the proportion of cases with comorbidities was observed over the study period.

Detection of another infectious pathogen (in addition to pertussis) was coded in $17.4 \%$ of cases $(n=65)$, with the majority of co-detections due to respiratory syncytial virus $(53.8 \%, \mathrm{n}=35)$. Other co-detections included adenovirus $(\mathrm{n}=6)$, bacterial $(\mathrm{n}=6)$, 'virus-other' $(\mathrm{n}=5)$, parainfluenzae $(\mathrm{n}=4)$, two Haemophilus influenzae type $B$ co-infections $(2000,2002)$ and two influenza co-infections $(2007,2008)$. Although the proportion of cases with co-detection fluctuated from year to year, the lowest occurring in $2013(5.6 \%, \mathrm{n}=1)$ and highest in $2008(37.5 \%, \mathrm{n}=6)$, there was no clear increasing or decreasing trend over the study period. Cases in whom co-detection of infection occurred were significantly older than those with pertussis only (mean (SD) 1.3 (3.3) vs 0.4 (1.5) years, respectively, mean difference (MD) 0.9 years, $95 \%$ CI 0.4 to 1.4 years, $p=0.0008$ ), and the proportion of cases with co-detection increased with increasing age $(<6$ weeks: $12.2 \%, 6$ weeks to $<4$ months: $18.1 \%, 4$ to $<6$ months: $21.4 \%, 6$ months to $<1$ year: $26.7 \%$, >1 year: $35.7 \%)$. Compared with cases of pertussis only $(n=308)$, those with co-infection $(n=65)$ had a significantly longer mean duration of invasive ventilation (mean (SD) 2.0 (6.6) vs 7.4 (26.3) days, respectively, MD 5.4 days, $95 \%$ CI 2.1 to 8.7 days, $\mathrm{p}=0.0016)$, and had a longer mean length of ICU stay (mean (SD) 5.4 (9.1) vs 10.1 (26.0) days, respectively, MD 4.7 days, $95 \%$ CI 1.1 to 8.4 days, $\mathrm{p}=0.01$ ). There was no significant difference in deaths between cases of pertussis only, and cases with co-detection $(6.5 \%$ vs $4.6 \%$, respectively, $\mathrm{RR}=0.7,95 \% \mathrm{CI}$ 0.2 to $2.3, \mathrm{p}=0.57$ ).

Cases stayed in ICU for a median of 3.6 days (range 0 209 days), with $77.5 \%$ of cases staying in ICU for $<7$ days, $15.5 \%$ staying between 7 and $<14$ days, $6.4 \%$ of cases staying between 14 and $<50$ days, and only two cases 
Table 1 Demographics and admission characteristics of pertussis-related intensive care unit (ICU) admissions, 1997-2013

\begin{tabular}{|c|c|c|c|c|c|c|}
\hline Year of admission & 1997-2000 & 2001-2004 & 2005-2008 & 2009-2012 & 2013* & Total \\
\hline Number of participating ICUs† & $7-9$ & $9-14$ & $13-19$ & 19-20 & 21 & $7-21$ \\
\hline $\begin{array}{l}\text { Pertussis-related admissions } \\
\mathrm{N} \text { (per cent of total pertussis admissions }\end{array}$ & $47(12.6)$ & $66(17.7)$ & $45(12.1)$ & $197(52.8)$ & $18(4.8)$ & $373(100)$ \\
\hline $\begin{array}{l}\text { Pertussis-related ICU admissions per } \\
1000 \text { all-cause ICU admissions (total } \\
\text { all-cause ICU admissions) }\end{array}$ & $2.2(21263)$ & $2.7(24636)$ & $1.6(27385)$ & $6.4(30954)$ & $1.9(9232)$ & $3.3(113$ 197) \\
\hline $\begin{array}{l}\text { Sex } \\
\text { Male-N (\%) }\end{array}$ & $25(54.3)$ & $41(62.1)$ & $22(48.9)$ & $85(43.2)$ & $9(50.0)$ & $182(48.9)$ \\
\hline Ethnicity & 5 of $46(10.9)$ & 8 of $66(12.1)$ & 1 of $16(6.3)$ & 4 of 45 (8.9) & 0 of $10(0)$ & 18 of $183(9.8)$ \\
\hline $\begin{array}{l}\text { Aboriginal and Torres Strait Islander } \\
\text { peoples-number with ethnicity recordec } \\
\text { (\%) } \\
\text { Age }\end{array}$ & & & & & & \\
\hline$<6$ weeks & $24(51.1 \%)$ & $25(38.9 \%)$ & $12(26.7 \%)$ & $87(44.2 \%)$ & $8(44.4 \%)$ & $156(41.8 \%)$ \\
\hline 6 weeks to $<4$ months & $21(44.7 \%)$ & $35(53.0 \%)$ & $23(51.1 \%)$ & $72(36.6 \%)$ & $9(50.0 \%)$ & $160(42.9 \%)$ \\
\hline 4 to $<6$ months & $2(4.3 \%)$ & $0(0 \%)$ & $2(4.4 \%)$ & $10(5.1 \%)$ & $0(0 \%)$ & $14(3.8 \%)$ \\
\hline 6 months to $<1$ year & $0(0 \%)$ & $2(3.0 \%)$ & $4(8.9 \%)$ & $9(4.6 \%)$ & $0(0 \%)$ & $15(4.0 \%)$ \\
\hline$\geq 1$ year & $0(0 \%)$ & $4(6.1 \%)$ & $4(8.9 \%)$ & $19(9.6 \%)$ & $1(5.6 \%)$ & $28(7.5 \%)$ \\
\hline Median age (range) & $\begin{array}{l}42 \text { days } \\
\text { (17 to } 152 \text { days) }\end{array}$ & $\begin{array}{l}49 \text { days ( } 19 \text { days to } \\
14.6 \text { years) }\end{array}$ & $\begin{array}{l}62 \text { days ( } 4 \text { days } \\
\text { to } 15.2 \text { years) }\end{array}$ & $\begin{array}{l}48 \text { days }(0 \text { days to } \\
15.9 \text { years) }\end{array}$ & $\begin{array}{l}45.5 \text { days ( } 23 \text { days } \\
\text { to } 8.4 \text { years) }\end{array}$ & $\begin{array}{l}48 \text { days ( } 0 \text { days to } \\
15.9 \text { years) }\end{array}$ \\
\hline \multicolumn{7}{|c|}{$\begin{array}{l}\text { Case state/territory of residence } \neq \\
\mathrm{N} \text { (per cent of total pertussis-related admissions); total all-cause ICU admissions }\end{array}$} \\
\hline Australian Capital Territory & $0(0.0) ; \mathrm{ND}$ & $0(0.0) ; 110$ & $0(0.0) ; 112$ & $1(0.5) ; 121$ & $0(0.0) ; 26$ & $1(0.3) ; 369$ \\
\hline New South Wales & $16(34.0) ; 5896$ & 11 (17.5); 7217 & 25 (56.8); 8037 & 70 (35.9); 9274 & 4 (22.2); 2526 & 126 (34.3); 32950 \\
\hline Northern Territory & $1(2.1) ; \mathrm{ND}$ & 3 (4.8); ND & $2(4.5) ; 222$ & $1(0.5) ; 243$ & $0(0.0) ; 83$ & 7 (1.9); 548 \\
\hline Queensland & 10 (21.3); 5201 & 11 (17.5); 5697 & 5 (11.4); 7177 & 43 (22.1); 7984 & 2 (11.1); 2843 & 71 (19.3); 28902 \\
\hline South Australia & $3(6.4) ; 2345$ & 12 (19.0); 2265 & $4(9.1) ; 2170$ & 9 (4.6); 2179 & $0(0.0) ; 555$ & $28(7.6) ; 9514$ \\
\hline Tasmania & $0(0.0) ; 62$ & $0(0.0) ; 163$ & $0(0.0) ; 338$ & 9 (4.6); 853 & $2(11.1) ; 215$ & 11 (3.0); 1631 \\
\hline Victoria & $3(6.4) ; 4953$ & 16 (25.4); 5699 & 5 (11.4); 6272 & 50 (25.6); 7228 & 10 (55.6); 2185 & 84 (22.9); 26337 \\
\hline Western Australia & 14 (29.8); 2806 & 10 (15.9); 3212 & 36.83057 & 12 (6.2); 3072 & $0(0.0) ; 799$ & 39 (10.6); 12946 \\
\hline $\begin{array}{l}\text { Patients with comorbidities } \\
\mathrm{N}(\%)\end{array}$ & $5(10.6)$ & $7(10.6)$ & $9(20.0)$ & $30(15.2)$ & $1(5.6)$ & $52(13.9)$ \\
\hline $\begin{array}{l}\text { Patients with infectious agent } \\
\text { co-detection } \\
\mathrm{N}(\%)\end{array}$ & $5(10.6)$ & $7(10.6)$ & $14(31.1)$ & $38(19.3)$ & $1(5.6)$ & $65(17.4)$ \\
\hline $\begin{array}{l}\text { Length of ICU stay } \\
\text { Median (range) }\end{array}$ & $\begin{array}{l}3.6 \text { days } \\
(<1-35 \text { days })\end{array}$ & $\begin{array}{l}3.7 \text { days } \\
(<1-36 \text { days })\end{array}$ & $\begin{array}{l}3.6 \text { days } \\
(<1-50 \text { days })\end{array}$ & $\begin{array}{l}3.4 \text { days } \\
(<1-209 \text { days })\end{array}$ & $\begin{array}{l}6.1 \text { days } \\
\text { (1-11 days) }\end{array}$ & $\begin{array}{l}3.6 \text { days } \\
\text { (<1-209 days) }\end{array}$ \\
\hline $\begin{array}{l}\text { Respiratory support required during 1st } \\
\text { hour of ICU admission§ञ } \\
\mathrm{N}(\%)\end{array}$ & $16(34.0)$ & $22(33.8)$ & $21(46.7)$ & $67(34.0)$ & $7(38.9)$ & $133(35.7)$ \\
\hline
\end{tabular}




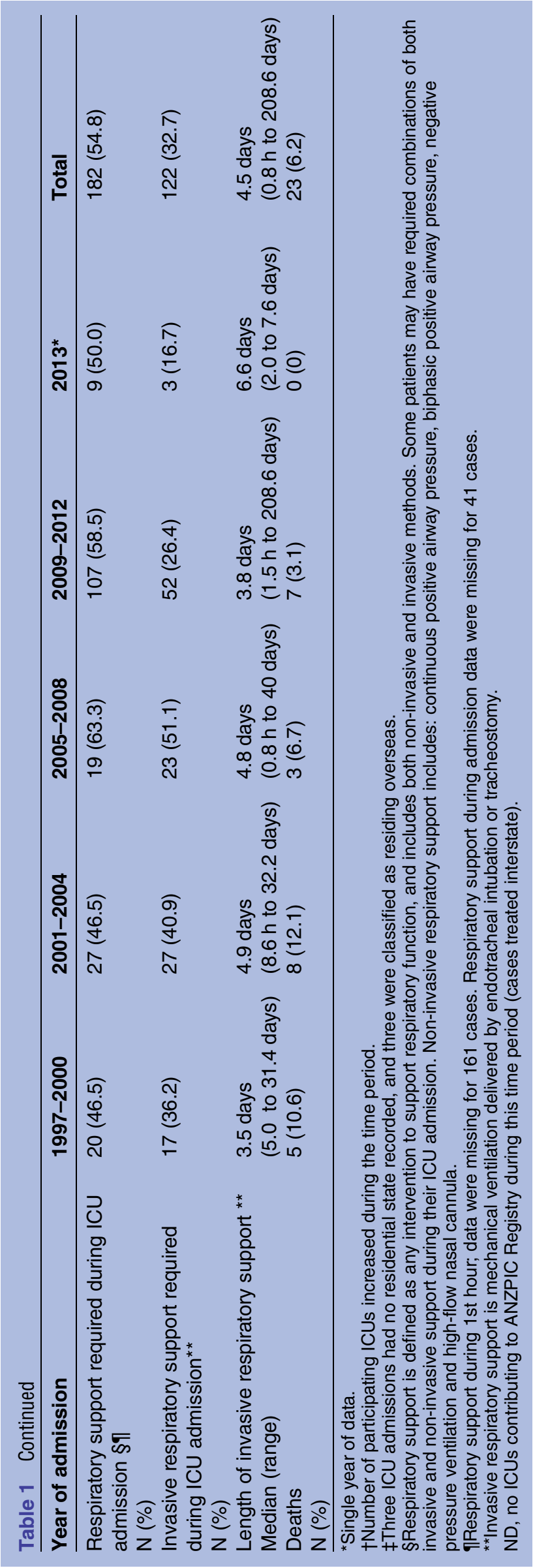

$(0.5 \%)$ staying in ICU for 50 days and longer (120 and 209 days). No significant difference was observed between age at admission ( $<4$ vs $\geq 4$ months) and length of ICU stay (mean (SD) 5.8 (9.3) vs 8.6 (27.4) days, respectively, MD 2.8 days, $95 \%$ CI -1.1 to 6.7 days, $\mathrm{p}=0.16)$.

Of all pertussis cases, approximately half (54.8\%) required some form of respiratory support during their ICU admission, with $35.7 \%$ needing respiratory support during the first hour (table 1). Invasive respiratory support was required by $32.7 \%$ of pertussis ICU admissions, and the median time of invasive support was 2.7 days (range $0.1 \mathrm{~h}$ to 196.1 days). Children aged $\geq 4$ months appeared to have a longer point estimate for mean duration of invasive respiratory support compared to infants aged $<4$ months, however, this finding was not statistically significant (mean (SD) 5.3 (27.6) vs 2.5 (7.1) days, respectively, MD 2.8 days, $95 \%$ CI -0.8 to 6.3 days, $\mathrm{p}=0.13$ ).

Over the study period, there were 23 recorded deaths among pertussis-related ICU admissions: 12 in infants aged $<6$ weeks (of $n=156,7.7 \%$ ), 8 in infants aged between 6 weeks and $<4$ months (of $\mathrm{n}=160,5.0 \%$ ), and the remaining 3 were in children aged over 12 months (of $\mathrm{n}=57,5.3 \%$ ). Infants aged $<6$ weeks did not have a significantly higher risk of death compared to older infants and children (RR $1.5,95 \%$ CI 0.7 to $3.4, \mathrm{p}=0.3$ ). The highest number of deaths occurred between 2001 and $2004(\mathrm{n}=8)$, and between 2009 and $2012(\mathrm{n}=7)$. As a percentage of all influenza-related ICU admissions, deaths were highest in 1997-2000 (10.6\%, n=5) and 2001-2004 (12.1\%, n=8). No deaths were recorded during 2013.

\section{DISCUSSION}

There were 373 paediatric patients with pertussis-related ICU admissions between 1997 and 2013. Of these, $84.7 \%$ occurred in infants aged $<4$ months, and approximately half $(53 \%)$ occurred during the most recent Australian pertussis epidemic period (2009-2012). While it is reassuring that few ICU admissions occurred among age groups that can be protected by vaccination ( $\geq 4$ months old), a finding that is consistent with the existing literature on pertussis-related hospitalisations, ${ }^{5} 68911$ our results indicate that more needs to be done to protect young infants $(<4$ months) who are most vulnerable to severe disease. Interestingly, the proportion of admissions requiring invasive ventilation increased over the study period, while the proportion of deaths declined from a peak in 1997-2000 (likely associated with an outbreak of pertussis in $1996-1997^{16}$ ), however, it is unclear whether this reflects better clinical management of pertussis or a change in disease severity. In the literature, there are very limited data available about pertussis ICU admissions, which are an important indicator of disease severity, falling between hospitalisation and death. While our findings were mostly 
Figure 1 Pertussis-related paediatric intensive care unit (ICU) admissions, Australia, 1997-2013, by year and age at admission.

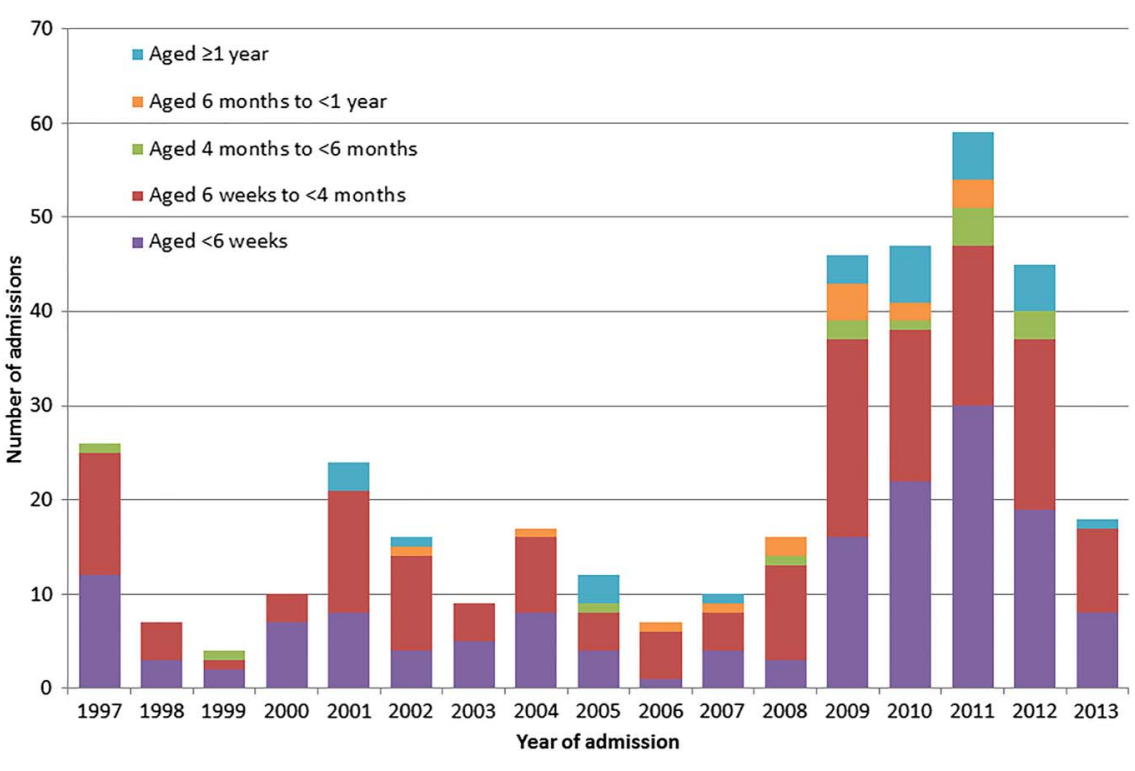

consistent with the studies we could identify focusing on pertussis ICU admissions, ${ }^{17-22}$ only one of these studies was Australian (based in Melbourne),${ }^{19}$ and only one was published in the last 5 years, ${ }^{21}$ limiting our ability to draw comparisons.

Infants aged $<6$ months are at highest risk for morbidity and mortality associated with pertussis infection. Australian vaccination schedules have been altered over time in an effort to better target protection to this group. ${ }^{3}$ From 2009, in response to increasing pertussis notifications across Australia, cocoon vaccination strategies were implemented at state level between 2009 and 2012 (programme timing and eligibility varied by state). ${ }^{7}$ Cocoon strategies aim to provide newborn infants with protection by vaccinating those around them in order to reduce the risk of transmission. We did not observe a decrease in ICU admissions among infants aged $<6$ months related to the cocoon programmes, however, these programmes coincided with record high pertussis incidences which may have masked any programme-related decline in cases.

Additionally, in early 2011, the National Immunisation Schedule was updated with a recommendation to provide the first pertussis vaccine dose at 6 weeks of age (rather than at 2 months) in an effort to provide infants with some level of protection as early as possible. By late 2011, five states (NSW, Australian Capital Territory (ACT), TAS, QLD and VIC) had about $50-70 \%$ of infants vaccinated with their first dose between 6 and $<8$ weeks of age, while other states were slower to implement the change (SA 40\%, Northern Territory (NT) $30 \%$, WA 20\%). ${ }^{23}$ A study by Foxwell and colleagues estimated that this schedule change would be associated with an annual reduction of up to $10 \%$ of pertussisrelated hospitalisations. ${ }^{24}$ Our data did not show any decline in pertussis ICU admissions among infants aged 6-8 weeks following the recommendation, although 2 years (2012-2013) may not be a long enough
Figure 2 Annual cumulative incidence of pertussis-related admissions to contributing ANZPIC Registry intensive care units (ICUs) ${ }^{*}$ and national pertussis notifications by age group ( $<1$ year and 1 to $<16$ years), per 100000 child-years, Australia, 1997-2013 ( ${ }^{*}$ The pertussis-related ANZPIC Registry ICU admissions presented in this figure will be an under-representation of all pertussis-related paediatric ICU admissions in Australia due to non-participation of some ICUs that admit children, including adult ICUs that do not report their data to the ANZPIC Registry).

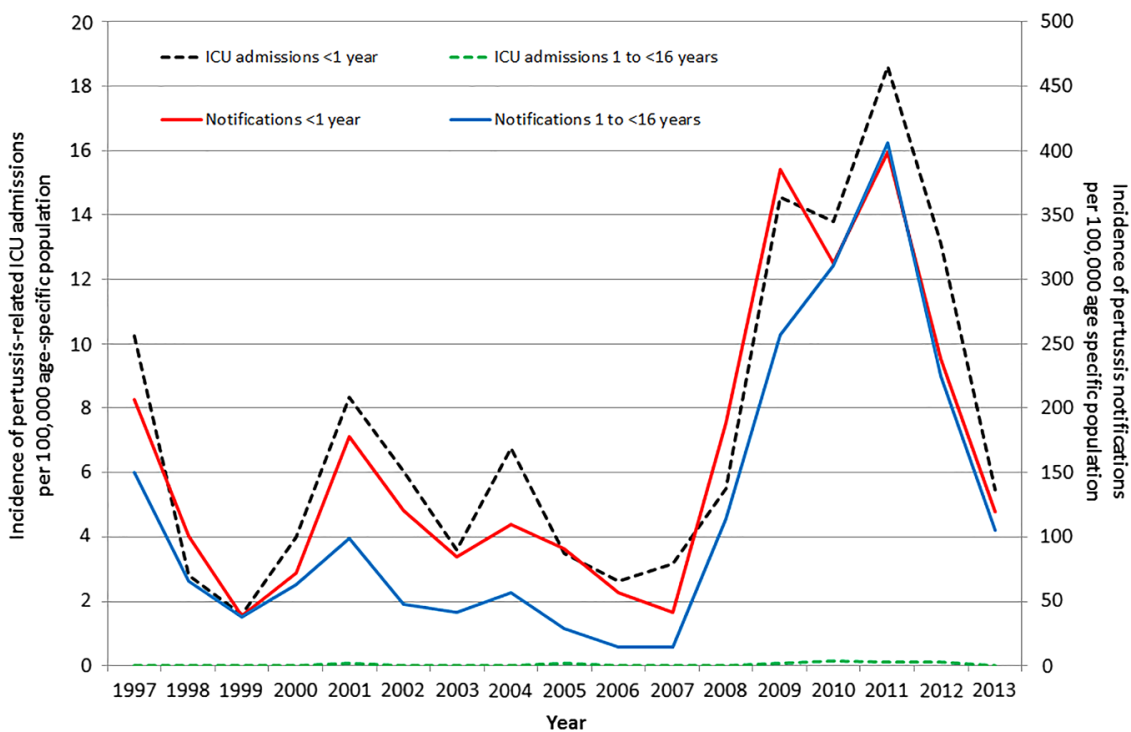


timeframe to see the full impact of this change, and again, any reductions in incidence may have been masked by the pertussis epidemic.

Immunisation status is not part of the set of data recorded for paediatric ICU admissions in the ANZPIC Registry. While it would be ideal to have the immunisation status of cases, it is worth noting only $11.5 \%$ of admissions occurred in age groups eligible to have been fully vaccinated ( $\geq 6$ months). The remainder of admissions were infants either too young to have received any vaccine doses $(<6$ weeks, $41.8 \%)$ or who may have been partially vaccinated with one or two doses (6 weeks to $<6$ months, $46.7 \%$ ).

While the ANZPIC Registry contains national data, and has provided an indication of pertussis-related ICU admissions across Australia, it may have underestimated the number of ICU admissions for a number of reasons. First, any admissions to ICUs not contributing to the ANZPIC Registry would have been missed in our analysis. In the earlier years of this study, fewer general ICUs contributed paediatric data to the ANZPIC Registry, however, the number of missing cases is expected to be low as all eight large specialist PICUs (which account for the vast majority of Australian paediatric ICU admissions) have participated in the ANZPIC Registry since $1997 .^{12}$ Second, as our study used data from an existing database, and did not include a medical chart review or diagnostic testing results, we were entirely reliant on the accuracy of existing ANZPIC Registry coding, which has not previously been validated. We will have missed any real cases not coded as 'pertussis' or 'pertussis syndrome', as well as prematurity and any co-detections or comorbidities not listed in one of the diagnosis fields. Inclusion of diagnosis codes is highly dependent on clinician awareness, diagnostic testing and perceived importance of the illness. ${ }^{25}$ Improvements in diagnostic testing, with the widespread use of PCR from 2007 onwards, ${ }^{26}$ as well as high media coverage (eg, following infant deaths and during the 2009-2012 epidemic), may have influenced pertussis testing and awareness among clinicians primarily during the latter part of our study period. Additionally, the likelihood of identifying co-infecting viruses is likely to have improved over time with increasing use of multiplex PCR. Unfortunately, it is not possible to measure the impact of diagnostic testing changes on awareness and/ or ICU admission coding, as diagnostic data are not available in the ANZPIC Registry. We hypothesise, however, that it is more likely that pertussis cases and co-detections were missed earlier in the study period, although the number missing cannot be quantified.

Even with protective vaccination strategies such as cocooning, and advancing the first dose to 6 weeks of age, infants, particularly under 4 months of age, continue to be at risk. Both maternal and neonatal vaccination are being assessed as possible solutions. ${ }^{1}{ }^{27-31}$ Assessment of the Public Health England maternal pertussis vaccination programme (which started in 2012) found vaccine effectiveness of $91 \%$ against confirmed pertussis in infants $<2$ months of age. ${ }^{27} 30 \mathrm{~A}$ birth dose of pertussis vaccine has also been shown to induce protective antibody responses, and therefore, protection against pertussis, prior to 6 months of age, but so far study sizes have been small. ${ }^{29}$ In March 2015, the Australian Government recommended a pertussis booster for pregnant women during the third trimester of pregnancy, and all states/territories now have locally funded programmes. The results from the UK are encouraging, with regard to coverage as well as safety and effectiveness, ${ }^{27} 303233$ however, there are significant barriers to uptake in Australia that will need to be overcome to achieve similar outcomes. ${ }^{34}$ Evaluations of these programmes and their impact on pertussis epidemiology will be an important area of research over the coming years.

\section{CONCLUSION}

Severe pertussis cases, requiring ICU admission, continue to occur primarily in infants too young to be fully protected from active immunisation. More needs to be done to protect these high-risk infants. In Australia, implementation of maternal immunisation programmes in all states and territories offers the hope of much better disease control in this age group. If coverage is high, we can expect reductions in pertussis-related ICU admissions and mortalities in infants.

\section{Author affiliations}

${ }^{1}$ UQ Child Health Research Centre, School of Medicine, The University of Queensland, Brisbane, Queensland, Australia

${ }^{2}$ School of Public Health, The University of Queensland, Brisbane,

Queensland, Australia

${ }^{3}$ Division of Critical Care, Lady Cilento Children's Hospital, South Brisbane, Queensland, Australia

${ }^{4}$ Academic Discipline of Paediatrics and Child Health, School of Medicine, The University of Queensland, Brisbane, Queensland, Australia

${ }^{5}$ Communicable Diseases Branch, Queensland Health, Brisbane, Queensland, Australia

Acknowledgements The authors thank the intensivists, data managers and other staff in the participating ICUs for contributions to the ANZPIC Registry, and Jan Alexander for her assistance with the data request. The ANZPIC Registry is supported by the Australian and New Zealand Intensive Care Society, the Ministry of Health (New Zealand), and State and Territory Health Departments through the Australian Health Ministers Advisory Council. Ms Kaczmarek is the recipient of a Sidney Myer Health Scholarship, and receives student support from the Queensland Children's Medical Research Institute, The University of Queensland School of Public Health, and The University of Queensland Child Health Research Centre. A/Prof Lambert is supported by an Early Career Fellowship from the Australian Government National Health and Medical Research Council and a people support grant from the Queensland Children's Hospital Foundation.

Contributors MCK, RSW, JAM, MGC and SBL contributed to the study design and the interpretation of the results and revision of the manuscript. MCK obtained the data, conducted the data analysis and drafted the manuscript. All authors read and approved the final manuscript.

Funding This research received no specific grant from any funding agency in the public, commercial or not-for-profit sectors.

Competing interests SBL reports not having shares, paid employment, or consultancies with any influenza vaccine manufacturer; he has been an 
investigator on vaccine and epidemiological studies sponsored by bioCSL, Merck, GSK, Novartis and Sanofi; his institute has received honoraria from Merck for talks he has given on rotavirus epidemiology and vaccines. MCK, RSW, JAM, and MGC declare that they have no competing interests.

Ethics approval Children's Health Services Queensland Human Research Ethics Committee.

Provenance and peer review Not commissioned; externally peer reviewed.

Data sharing statement No additional data are available.

Open Access This is an Open Access article distributed in accordance with the Creative Commons Attribution Non Commercial (CC BY-NC 4.0) license, which permits others to distribute, remix, adapt, build upon this work noncommercially, and license their derivative works on different terms, provided the original work is properly cited and the use is non-commercial. See: http:// creativecommons.org/licenses/by-nc/4.0/

\section{REFERENCES}

1. Mclntyre P, Wood N. Pertussis in early infancy: disease burden and preventive strategies. Curr Opin Infect Dis 2009;22:215-23.

2. Glanz JM, Narwaney KJ, Newcomer SR, et al. Association between undervaccination with diphtheria, tetanus toxoids, and acellular pertussis (DTaP) vaccine and risk of pertussis infection in children 3 to 36 months of age. JAMA Pediatr 2013;167:1060-4.

3. Australian Government Department of Health. Macartney K (ed). Chapter 4.12-Pertussis. In: The Australian immunisation handbook 10th edn. Canberra, Australia: Commonwealth of Australia, 2013, pp 302-306. (Updated June 2015). http://www.immunise.health.gov.au/ internet/immunise/publishing.nsf/Content/Handbook10-home

4. Spokes PJ, Quinn HE, McAnulty JM. Review of the 2008-2009 pertussis epidemic in NSW: notifications and hospitalisations. N S W Public Health Bull 2010;21:167-73.

5. Marshall $\mathrm{H}$, Clarke $\mathrm{M}$, Rasiah $\mathrm{K}$, et al. Predictors of disease severity in children hospitalized for pertussis during an epidemic. Pediatr Infect Dis J 2015;34:339-45.

6. Elliott E, Mclntyre P, Ridley G, et al. National study of infants hospitalized with pertussis in the acellular vaccine era. Pediatr Infect Dis J 2004;23:246-52.

7. National Centre for Immunisation Research \& Surveillance. Significant events in diphtheria, tetanus and pertussis vaccination practice in Australia. 2015. http://www.ncirs.edu.au/immunisation/ history/Diphtheria-tetanus-pertussis-history-July-2012.pdf (accessed Jul 2015).

8. Wood N, Quinn HE, Mclntyre P, et al. Pertussis in infants: preventing deaths and hospitalisations in the very young. J Paediatr Child Health 2008;44:161-5

9. Pillsbury A, Quinn HE, Mclntyre PB. Australian vaccine preventable disease epidemiological review series: pertussis, 2006-2012. Commun Dis Intell Q Rep 2014;38:E179-94.

10. Campbell $P$, Mclntyre $P$, Quinn $H$, et al. Increased population prevalence of low pertussis toxin antibody levels in young children preceding a record pertussis epidemic in Australia. PLOS ONE 2012;7:e35874.

11. Quinn HE, Snelling TL, Macartney KK, et al. Duration of protection after first dose of acellular pertussis vaccine in infants. Pediatrics 2014;133:e513-19.

12. Alexander J, Millar J, Slater A, et al. Report of the Australian and New Zealand Paediatric Intensive Care Registry, 2013. Australian and New Zealand Intensive Care Society (ANZICS), 2014 http:// www.anzics.com.au/Downloads/2013\%20ANZPICR\%20Annual\% 20Report.pdf (accessed Jul 2015).

13. Slater A, Shann F, McEniery J, et al. The ANZPIC registry diagnostic codes: a system for coding reasons for admitting children to intensive care. Intensive Care Med 2003;29:271-7.
14. Australian Government Department of Health. Australian national notifiable diseases case definitions: Pertussis case definition 2014 http://www.health.gov.au/internet/main/publishing.nsf/Content/ cdna-casedefinitions.htm (accessed Jul 2015).

15. Australian Bureau of Statistics. 3101.0-Australian Demographic Statistics. 2013 (updated 16 July 2014). http://www.abs.gov.au/ AUSSTATS/abs@.nsf/DetailsPage/3101.0Dec\%202013? OpenDocument (accessed Jul 2014).

16. Williams GD, Matthews NT, Choong RK, et al. Infant pertussis deaths in New South Wales 1996-1997. Med J Aust 1998;168: 281-3

17. Crowcroft NS, Booy R, Harrison T, et al. Severe and unrecognised: pertussis in UK infants. Arch Dis Child 2003;88:802-6.

18. Ranganathan S, Tasker R, Booy R, et al. Pertussis is increasing in unimmunised infants: is a change in policy needed? Arch Dis Child 1999;80:297-9.

19. Namachivayam P, Shimizu K, Butt W. Pertussis: severe clinical presentation in pediatric intensive care and its relation to outcome. Pediatr Crit Care Med 2007;8:207-11.

20. Surridge J, Segedin ER, Grant CC. Pertussis requiring intensive care. Arch Dis Child 2007:92:970-5.

21. Berger JT, Carcillo JA, Shanley TP, et al. Critical pertussis illness in children: a multicenter prospective cohort study. Pediatr Crit Care Med 2013;14:356-65.

22. Greenberg DP, Bamberger E, Ben-Shimol S, et al. Pertussis is under diagnosed in infants hospitalized with lower respiratory tract infection in the pediatric intensive care unit. Medical Science Monitor 2007;13:475-80.

23. Hull BP, Dey A, Menzies RI, et al. Immunisation coverage annual report, 2011. Commun Dis Intell Q Rep 2013;37:E291-312.

24. Foxwell AR, Mclntyre $P$, Quinn $H$, et al. Severe pertussis in infants: estimated impact of first vaccine dose at 6 versus 8 weeks in Australia. Pediatr Infect Dis J 2011;30:161-3.

25. Kenyon C, Banerjee E, Sweet K, et al. Assessing the impact of a pertussis active surveillance program on provider testing behavior, Minnesota 2005-2009. Am J Public Health 2014;104: e34-9.

26. Kaczmarek MC, Valenti L, Kelly HA, et al. Sevenfold rise in likelihood of pertussis test requests in a stable set of Australian general practice encounters, 2000-2011. Med J Aust 2013;198: 624-8.

27. Amirthalingam $\mathrm{G}$, Andrews $\mathrm{N}$, Campbell $\mathrm{H}$, et al. Effectiveness of maternal pertussis vaccination in England: an observational study. Lancet 2014;384:1521-8.

28. Swamy GK, Wheeler SM. Neonatal pertussis, cocooning and maternal immunization. Expert Rev Vaccines 2014;13:1107-14.

29. Wood N, Marshall $\mathrm{H}$, White OJ, et al. Antibody and cell-mediated immunity to pertussis 4 years after monovalent acellular pertussis vaccine at birth. Pediatr Infect Dis J 2014;33:511-17.

30. Dabrera G, Amirthalingam G, Andrews N, et al. A case-control study to estimate the effectiveness of maternal pertussis vaccination in protecting newborn infants in England and Wales, 2012-2013. Clin Infect Dis 2015;60:333-7.

31. Cherry JD. Tetanus-diphtheria-pertussis immunization in pregnant women and the prevention of pertussis in young infants. Clin Infect Dis 2015;60:338-40.

32. Public Health England. Laboratory confirmed cases of pertussis reported to the enhanced pertussis surveillance programme in England during January to March 2015 (Q1/2015). 2015 (updated 26 June 2015). https://www.gov.uk/government/uploads/system/ uploads/attachment_data/file/439029/hpr2215_prtsss.pdf (accessed Jul 2015).

33. Donegan K, King B, Bryan P. Safety of pertussis vaccination in pregnant women in UK: observational study. BMJ 2014;349: g4219.

34. Hayles EH, Cooper SC, Wood N, et al. Pertussis booster vaccination in pregnancy: women who had it compared to those who waited. Procedia Vaccinol 2015;9:59-65 
Correction: Epidemiology of pertussis related paediatric

intensive care unit (ICU) admissions in Australia, 1997-2013:

an observational study

Kaczmarek MC, Ware RS, McEniery JA, et al. Epidemiology of pertussis related paediatric intensive care unit (ICU) admissions in Australia, 1997-2013: an observational study. BMJ Open 2016;6:e10386.

The penultimate sentence in the results section currently reads: 'As a percentage of all influenza-related ICU admissions, deaths were highest in $1997-2000(10.6 \%, \mathrm{n}=5)$ and 2001-2004 $(12.1 \%, \mathrm{n}=8)$.' Instead, the final sentence should be: 'As a percentage of all pertussis-related ICU admissions, deaths were highest in 1997-2000 (10.6\%, $\mathrm{n}=5)$ and 2001-2004 (12.1\%, n=8).'

Open Access This is an Open Access article distributed in accordance with the Creative Commons Attribution Non Commercial (CC BY-NC 4.0) license, which permits others to distribute, remix, adapt, build upon this work noncommercially, and license their derivative works on different terms, provided the original work is properly cited and the use is non-commercial. See: http://creativecommons.org/licenses/by-nc/4.0/

BMJ Open 2016;6:e010386corr1. doi:10.1136/bmjopen-2015-010386corr1 